\title{
Use of Response Surface Optimization Technique in Evaluating the Tool Wear in a Turning Machine Cutting Process
}

\author{
*SADA, SO \\ Department of Mechanical \& Production Engineering, Faculty of Engineering, Oleh Campus, Delta State University. Nigeria. Email \\ *Corresponding Author E-mail: samorosada@ gmail.com. 08034085480
}

\begin{abstract}
Response surface methodology (RSM) was used to evaluate the wear of a cutting tool during a turning machine cutting process. The data obtained reveals optimum values for this process as cutting speed $=1303 \mathrm{rev} / \mathrm{min}$, Feed Rate $=0.354(\mathrm{~mm} / \mathrm{min})$, Depth of cut $=0.458(\mathrm{~mm})$ at a minimized tool wear of 0.173 . With the use of the response surface optimization process, the experiment was planned, carried out and analyzed. Analysis of variance (ANOVA) was used to check the significance of the model, as well as identify process parameters with the most significant effect on the tool wear.
\end{abstract}

\section{DOI: https://dx.doi.org/10.4314/jasem.v22i4.7}

Copyright: Copyright $\left({ }^{\circ} 2018\right.$ Sada. This is an open access article distributed under the Creative Commons Attribution License (CCL), which permits unrestricted use, distribution, and reproduction in any medium, provided the original work is properly cited.

Dates: Received: 04 March 2018; Revised: 07April: 2018; Accepted: 18 April 2018

Keyword: Machining, Tool Wear, Optimization, Response Surface Methodology

Machining is one of the five groups of manufacturing processes which comprises casting, forming, powder metallurgy and joining (Nagendra and Mittal, 2007). From the time of the industrial revolution, machining has remained one of the core of the manufacturing industries and may be classified into two main groups as (i) cutting process with traditional machining (e.g., turning, milling, boring and grinding) and (ii) cutting process with modern machining (e.g., electrical discharge machining (EDM) and abrasive waterjet (AWJ)). Turning which is one of the cutting operations performed with traditional machining, is one in which the part is rotated as the cutting tool is held against it on a machine called a lathe. In optimizing the machining process parameters, the selection of machining process parameters is a very crucial part in order for the machine operations to be successful (Rao and Pawar, 2010). The machining parameters (cutting speed, feed rate, depth of cut) accelerate tool wear and it affects the surface finishing. The tool wear is directly related to the machining parameters (Musialek, 1999). Response surface methodology (RSM) is a useful statistical technique in analyzing and modeling data. It's a collection of mathematical and statistical techniques, which are useful for the modeling and analysis of engineering problems and developing, improving, and optimizing processes. It also has important applications in the design, development, and formulation of new products, as well as in the improvement of existing product designs, and it is an effective tool for constructing optimization models (Montgomery, 1991). The RSM comprises the designing of a set of experiments for adequate and reliable measurement of the true mean response of interest, the development of a mathematical model with best fits, finding the optimum set of experimental factors that produces maximum or minimum value of response, and finally representing the direct and interactive effects of process variables on two and three dimensional graphs. Flank wear has been traditionally emphasized more than crater wear during analysis of cutting tool wear. This is because of the more direct influence that flank wear has on the accuracy of the product. Among all the types of wear, flank wear and the resulting recession of the cutting edge affect the workpiece dimension, as well as quality, to a large extent. Flank wear also results in changes to the mechanics of the cutting process (Asibu, 1985), an increased tendency for chatter, and changes in the dimension of the product. This is why the single most significant type of wear that has drawn constant attention is flank wear. The current analysis is therefore restricted to wear on the flank of the cutting tool. The objective of this study is to use the response surface methodology optimization process in evaluating the tool wear in a turning machine cutting process.

\section{MATERIALS AND METHODS}

Experimental Design: The experiment was performed, with the identification of process parameters, their levels and the design of a design matrix. Based on related studies and machine handbooks, the 
independent process parameters affecting the flank wear performance and their ranges were identified and tabulated as shown in table 1.

Table 1: Cutting Parameters and Their Range

\begin{tabular}{lllll}
\hline Symbols & Parameters & Notation & Units & Level \\
\hline A & Cutting & $\mathrm{V}$ & $\mathrm{rev} / \mathrm{min}$ & $900-$ \\
& Speed & & & 1400 \\
$\mathrm{~B}$ & Feed Rate & $\mathrm{F}$ & $\mathrm{mm} / \mathrm{min}$ & $0.2-0.4$ \\
$\mathrm{C}$ & Depth of Cut & $\mathrm{T}$ & $\mathrm{Mm}$ & $0.4-1.6$ \\
\hline
\end{tabular}

Table 2: Central Composite Design Generated Design Matrix

\begin{tabular}{lllll}
\hline $\begin{array}{l}\text { Std } \\
\text { Order }\end{array}$ & $\begin{array}{l}\text { Run } \\
\text { Order }\end{array}$ & $\begin{array}{l}\text { Cutting Speed } \\
(\text { rev/min) }\end{array}$ & $\begin{array}{l}\text { Feed Rate } \\
(\mathrm{mm} / \mathrm{min})\end{array}$ & $\begin{array}{l}\text { Depth of } \\
\text { Cut }(\mathrm{mm})\end{array}$ \\
\hline 14 & 1 & 1150 & 0.3 & 2.0 \\
1 & 2 & 900 & 0.2 & 0.4 \\
7 & 3 & 900 & 0.4 & 1.6 \\
9 & 4 & 729.5 & 0.3 & 1.0 \\
15 & 5 & 1150 & 0.3 & 1.0 \\
16 & 6 & 1150 & 0.3 & 1.0 \\
8 & 7 & 1400 & 0.4 & 1.6 \\
11 & 8 & 1150 & 0.13 & 1.0 \\
5 & 9 & 900 & 0.2 & 1.6 \\
20 & 10 & 1150 & 0.3 & 1.0 \\
2 & 11 & 1400 & 0.2 & 0.4 \\
18 & 12 & 1150 & 0.3 & 1.0 \\
10 & 13 & 1570 & 0.3 & 1.0 \\
19 & 14 & 1150 & 0.3 & 1.0 \\
12 & 15 & 1150 & 0.47 & 1.0 \\
3 & 16 & 900 & 0.4 & 0.4 \\
13 & 17 & 1150 & 0.3 & 0.01 \\
17 & 18 & 1150 & 0.3 & 1.0 \\
4 & 19 & 1400 & 0.4 & 0.4 \\
6 & 20 & 1400 & 0.2 & 1.6 \\
\hline
\end{tabular}

In order to achieve the objective of the study, the experiment was designed statistically using the central composite design of the response surface methodology. The design matrix with a record of 20 experimental runs at three levels, was obtained as shown in table 2 .

Experimental Procedure: Before commencing the experiment, the tool height and the tool overhang were set using gauges. Thereafter, with the design matrix and experimental runs obtained earlier as tabulated in table 2 , the workpiece a mild steel $\operatorname{rod}(50 \mathrm{~mm} \times$ $120 \mathrm{~mm}$ long), was turned using a HSS tool on a Lathe machine (Heidenreich and Harbeck-Hamburg 250).The cutting component and the feed component of the cutting force were measured using an industrial engineering dynamometer (620 B). A tape rule model Fat Max Blade Armor 35 was used to measure the total cutting length a tool will cut effectively. The tool wear data were collected for each of the cutting conditions and recorded.

Statistical Analysis: The data was analyzed using response surface methodology, so as to fit the quadratic polynomial equation generated by the Design Expert software. In order to compare the observe response variable to the independent factor variables, multiple regressions were used to fit the coefficient of the polynomial model of the observe response. The quality of the fit of the model was evaluated using test of significance and analysis of variance (ANOVA). The fitted quadratic response model is described by Eqn 1: Where: $y$ is the response factor, $\beta_{o}$ is the intercept value, $\beta i(i=1,2, k)$ is the first order model coefficient, $\beta_{i j}$ is the interaction effect, and $\beta_{i i}$ represents the quadratic coefficients of $x_{i}$, and $e$ is the random error.

$$
y=\beta_{\mathrm{o}}+\sum_{i=1}^{k} \beta_{\mathrm{i}} x_{\mathrm{i}}+\sum_{j=1}^{k} \beta_{\mathrm{ii}} x_{\mathrm{i}}^{2}+\sum \sum_{i j} \beta_{\mathrm{i}} x_{\mathrm{i}} x_{\mathrm{i}}+\varepsilon \text { for } i<j \quad 1
$$

\section{RESULTS AND DISUSSIONS}

The result of the experiment were obtained and tabulated as shown in Table 3. With the use of design expert 11 software, the data was statistically analyzed using the response surface methodology. Analysis of variance (ANOVA) was employed to check the significance of the model. ANOVA is a statistical technique used to make inference based on analysis of the experimental data. Depicted in Table 3 are the results of test of significance for every regression coefficient. The model F-value (terms used to estimate effects) of 7.12 with low p-value $(<0.0025)$ reflected a high significance for the regression model. Considering the large F-values and the corresponding low p-values observed in Table 3 , the following model terms: cutting speed and depth of cut are remarkably significant and have very strong effects on the tool wear. Nevertheless, the linear term "depth of cut" with
F-value of 24.34 and p-value of 0.0006 , indicated the most significant model term. In addition to the analysis of variance, the goodness of fit statistics comprising the coefficient of determination $\left(\mathrm{R}^{2}\right)$ (which tells the quality of the model), adjusted $\mathrm{R}^{2}$ (a model term to check the $\mathrm{R}^{2}$ value) and the Predicted $\mathrm{R}^{2}$ (a model term that tells how well the model obtained is capable of making prediction) was used to tell how well the data fits the model. It should be noted that the $\mathrm{R}^{2}$ which is the coefficient of determination, should be at least 0.80 for the good fit of a model. Observation in this study showed that the $\mathrm{R}^{2}$ value of 0.8651 was obtained, an indication that the sample variation of $86.51 \%$ is attributed to the independent factors (cutting speed, feed rate and depth of cut). The value of the adjusted determination coefficient (Adj. $\mathrm{R}^{2}$ ) was 0.7436 and adeq. precision was 9.8184 , implying that the model proved suitable for the adequate representation of the 
actual relationship among the selected factors, a good model is expected to have a $R^{2}$ and Adj $R^{2}$ with very minimum difference and an adequate precision greater than 4 .
The developed regression model describing the factors of cutting speed, feed rate, depth of cut and their respective interactions is described in eqn 2 in terms of actual factors.

Tool Wear $=4.999-0.004 A-8.478 B-3.956 C+0.005 A B+0.002 A C+2.146 B C+4.687 A^{2}+2.576 B^{2}+0.621 C^{2}$

Table 3: Result of Tool Wear Experiment

\begin{tabular}{cccccc}
\hline Std Order & $\begin{array}{c}\text { Run } \\
\text { Order }\end{array}$ & $\begin{array}{l}\text { Cutting Speed } \\
(\mathrm{rev} / \mathrm{min})\end{array}$ & $\begin{array}{l}\text { Feed Rate } \\
(\mathrm{mm} / \mathrm{min})\end{array}$ & $\begin{array}{l}\text { Depth of Cut } \\
(\mathrm{mm})\end{array}$ & $\begin{array}{l}\text { Response } \\
\text { Tool Wear }(\mathrm{mm})\end{array}$ \\
\hline 14 & 1 & 1150 & 0.3 & 2.0 & 1.41 \\
1 & 2 & 900 & 0.2 & 0.4 & 0.31 \\
7 & 3 & 900 & 0.4 & 1.6 & 0.34 \\
9 & 4 & 729.5 & 0.3 & 1.0 & 0.31 \\
15 & 5 & 1150 & 0.3 & 1.0 & 0.34 \\
16 & 6 & 1150 & 0.3 & 1.0 & 0.36 \\
8 & 7 & 1400 & 0.4 & 1.6 & 2.21 \\
11 & 8 & 1150 & 0.13 & 1.0 & 0.29 \\
5 & 9 & 900 & 0.2 & 1.6 & 0.31 \\
20 & 10 & 1150 & 0.3 & 1.0 & 0.31 \\
2 & 11 & 1400 & 0.2 & 0.4 & 0.32 \\
18 & 12 & 1150 & 0.3 & 1.0 & 0.31 \\
10 & 13 & 1570 & 0.3 & 1.0 & 0.32 \\
19 & 14 & 1150 & 0.3 & 1.0 & 0.33 \\
12 & 15 & 1150 & 0.47 & 1.0 & 0.32 \\
3 & 16 & 900 & 0.4 & 0.4 & 0.31 \\
13 & 17 & 1150 & 0.3 & 0.01 & 0.32 \\
17 & 18 & 1150 & 0.3 & 1.0 & 0.32 \\
4 & 19 & 1400 & 0.4 & 0.4 & 0.32 \\
6 & 20 & 1400 & 0.2 & 1.6 & 1.21 \\
\hline
\end{tabular}

Table 3: Analysis of Variance

\begin{tabular}{lllllll}
\hline Source & Sum of Squares & $\mathbf{d f}$ & Mean Square & F-value & p-value & significant \\
Model & 4.16 & 9 & 0.4621 & 7.12 & 0.0025 & 0.0138 \\
A-Cutting Speed & 0.5769 & 1 & 0.5769 & 8.89 & 1.32 & 0.2777 \\
B-Feed Rate & 0.0855 & 1 & 0.0855 & 24.34 & 0.0006 \\
C-Depth of Cut & 1.58 & 1 & 1.58 & 1.81 & 0.2079 \\
AB & 0.1176 & 1 & 0.1176 & 14.57 & 0.0034 \\
AC & 0.945 & 1 & 0.9453 & 2.04 & 0.1833 \\
BC & 0.1326 & 1 & 0.1326 & 0.1906 & 0.6717 \\
$\mathrm{~A}^{2}$ & 0.0124 & 1 & 0.0124 & 0.1474 & 0.7091 \\
$\mathrm{~B}^{2}$ & 0.0096 & 1 & 0.0096 & 11.12 & 0.0076 & \\
$\mathrm{C}^{2}$ & 0.7215 & 1 & 0.7215 & 343.42 & & Significant \\
Residual & 0.6487 & 10 & 0.0649 & & & \\
Lack of Fit & 0.6468 & 5 & 0.1294 & & & \\
Pure Error & 0.0019 & 5 & 0.0004 & & & \\
Cor Total & 4.81 & 19 & & & & \\
\hline
\end{tabular}

Using the normal probability plots of the residuals, the adequacy of the model was also investigated to examine the residuals. The residuals, is the difference between the respective experimental response values and the predicted values. If the model is adequate, the points on the normal probability plots of the residuals should form a straight line. On the other hand, the plots of the residuals verses the predicted response should be structure less, that is, they should contain no obvious pattern. From the probability plots shown in Figure 6, it was observed that the residuals falls on a straight line implying that the errors are distributed normally.

This implies that the model proposed is adequate and there is no reason to suspect any violation of the independence or constant variance assumptions. Usually, the three-dimensional (3D) response surface plots are graphical representations of the regression equation for the optimization of the variables, and they are represented in Figures. 6a, 6b and 6c. Figure 8a, shows that the feed rate has very insignificant effect on the tool wear, whereas figure $8 b$ and $c$, shows a considerable decrease in the tool wear as the combined interaction of depth of cut and cutting speed (6b), depth of cut and feed rate increases. The curvatures nature of the 3D surfaces are represented in Figure 7. As the model is adequate these 3D surface plots can be used to estimate the tool wear for any suitable combination of the input parameters. Problems in multi response form have more than one response to a given situation. 


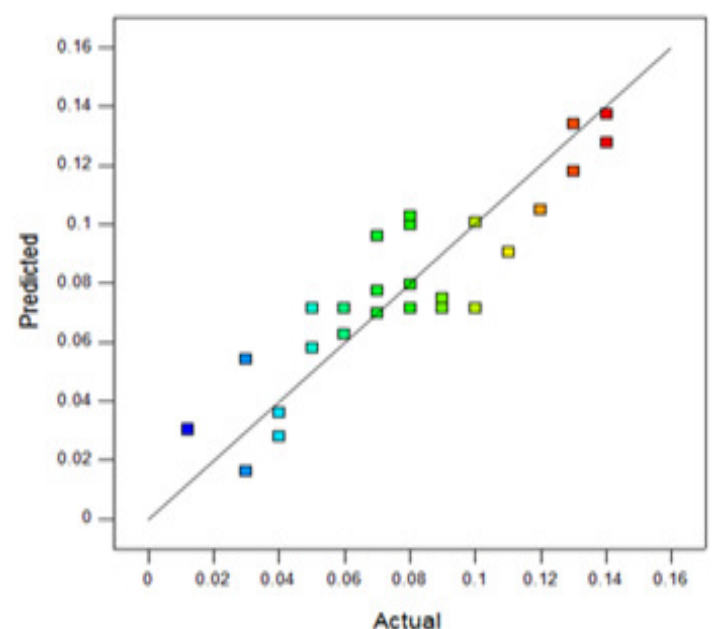

Fig 5: Plot of Observed versus Predicted Values of the Tool Wear
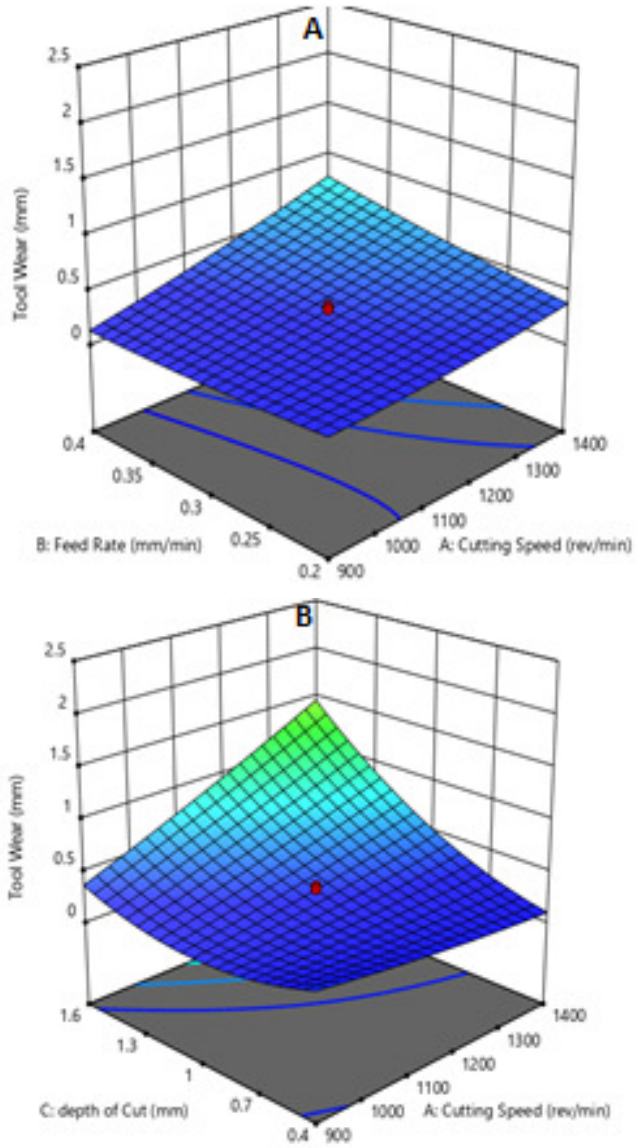

There are various techniques to optimize multi response problems. One of the most used methods to solve multi response surface problems is the desirability function. Because, optimization of all responses simultaneously is possible by combining them into a single objective function, which basically represents the relationship of all responses that are to be optimized (Aksezer, 2008).

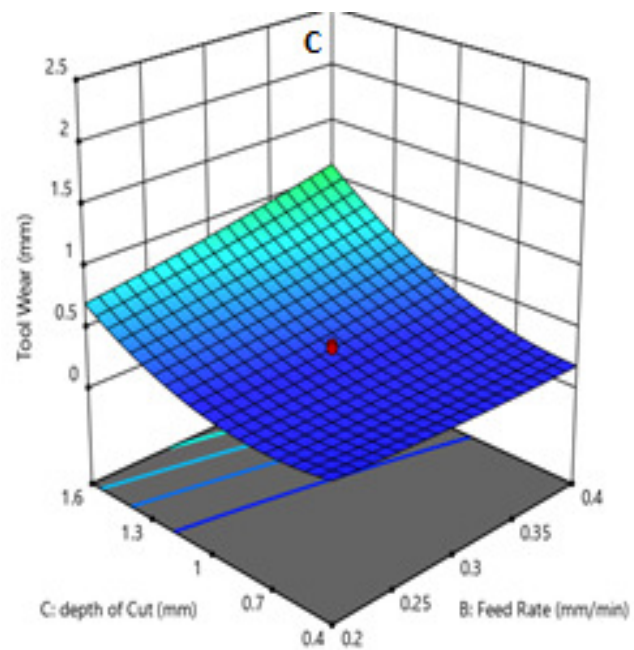

Fig6: surface plot of the combined effect the interaction versus the tool wear
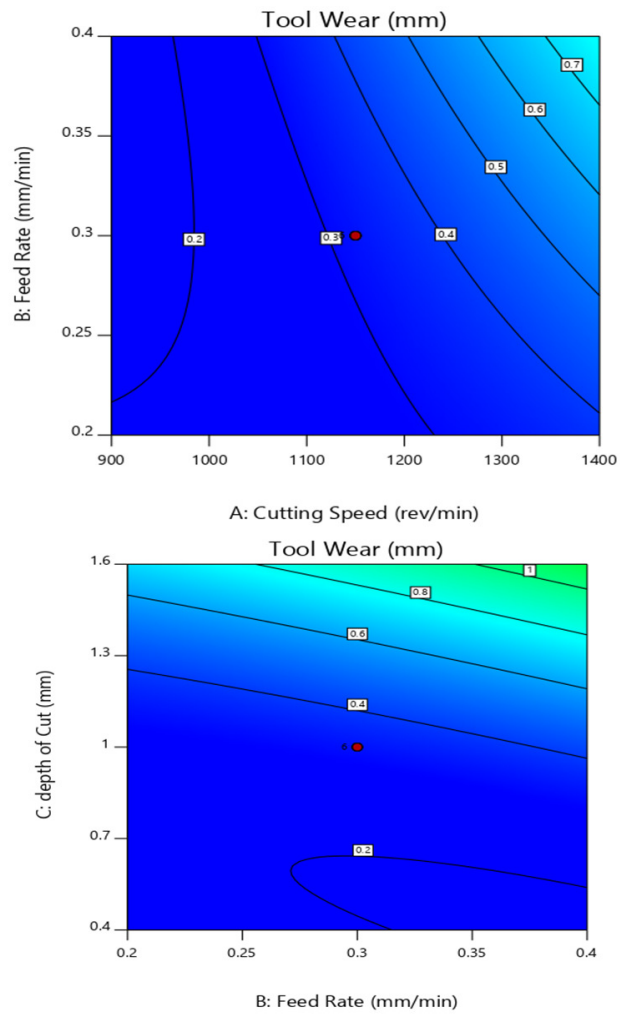

Fig7: Contour plots showing combined interactions versus the tool wear

The optimum values of the independent factors selected for the tool wear experiment were obtained by numerical optimization applying desirability function, using the Design-Expert software. The optimum values for this process were given as cutting speed= $1303 \mathrm{rev} / \mathrm{min}$, Feed Rate $=0.354(\mathrm{~mm} / \mathrm{min})$, Depth of cut $=0.458(\mathrm{~mm})$ at a minimized tool wear of 0.173 . 
Conclusion: The suitability of response surface methodology in modeling the tool wear in the turning process of a cutting tool, has been successfully studied. A mathematical model was developed, checked for significance using the analysis of variance (ANOVA) and used in making predictions. Results showed that the cutting speed and depth of cut were the most significant model terms. The results obtained from the model prediction were compared to the experimentally obtained values, the residue was within acceptable value. Using numerical optimization, optimum values for this process were cutting speed= $1303 \mathrm{rev} / \mathrm{min}$, Feed Rate $=0.354(\mathrm{~mm} / \mathrm{min})$, Depth of cut $=0.458(\mathrm{~mm})$ at a minimized tool wear of 0.173 .

Acknowledgement: The author would like to appreciate the management of Lee Engineering Company, Warri. For making available their mechanical workshop as well as providing all the facilities needed in conducting this experiments.

\section{REFERENCES}

Asibu, EK (1985). A transport-diffusion equation in metal cutting and its application to the analysis of the rate of flank wear. Trans. ASME, J. Eng. Ind. 107(2), 81-89.

Aksezer, CS (2008). On the sensitivity of desirability functions for multiresponse optimization, J. Ind. Manage. Opt. 4(4), 685-696.

Chelladurai, H; Jain, VK; Vyas, NS (2008). Development of a cutting tool condition monitoring system for high speed turning operation by vibration and strain analysis, Int. J. Adv. Manufacture. Tech. 37: 471-485.
Choudhury, SK; Jain, VK; Rama RC (1999). On-line monitoring tool wear in turning using a neural network. Int. J. Mach. Tools. 39, 489-504.

Montgomery, DC (1991). Design and Analysis of Experiments, p. 3, John Wiley and Sons, NY.

Musialek, K (1999).Role and importance of cutting fluids in high efficiency machining," The 2nd Seminar Workshop: Network Proceeding, EspooOtaniemi, Finland.

Nagendra PBS; Mittal, RK (2007). Elements of Manufacturing Processes. Prentice-Hall of India Private Limited.

Rao, R.V; Pawar, PJ (2010). Parameter optimization of a multi-pass milling process using nontraditional optimization algorithms. App. Soft Computing, 10(2), 445-456.

Sivasakthivel, PS; Murugan, VV; Sudhakaran, R (2010). Prediction of tool wear from machining parameters by response surface methodology in end milling. Int. J. of Eng. Sci. and Tech. 2 (6). $1780-1789$.

Yang, WH; Tarng, YS (1998). Design optimization of cutting parameters for turning operations based on the Taguchi method. J. Mat. Proc. Tech.34. 122129. 